\title{
Difference in Sleep Characteristics between Restless Leg Syndrome With and Without Periodic Limb Movement during Wakefulness
}

\author{
Yu Yong Shin, Jung-Ick Byun, Won Chul Shin \\ Department of Neurology, Kyung Hee University Hospital at Gangdong, Seoul, Korea \\ 각성 중 주기성사지운동 여부에 따른 하지불안증후군 환자의 수면 특성 차이에 대한 비교연구 \\ 신유용, 변정익, 신원철 \\ 강동경희대학교병원 신경과
}

Received November 19, 2018 Revised December 13, 2018 Accepted December 13, 2018

Address for correspondence Won Chul Shin, MD, PhD

Department of Neurology, Kyung Hee University Hospital at Gangdong, 892 Dongnam-ro, Gangdong-gu, Seoul 05278, Korea

Tel: $+82-2-440-6166$

Fax: +82-2-440-7262

E-mail: shinwc@khu.ac.kr
Objectives: Restless leg syndrome (RLS) is a common sensorimotor disorder and is frequently associated with periodic limb movement in sleep (PLMS). Also about one third of patient with RLS have periodic limb movement during wakefulness (PLMW). However there is little research on the correlation between PLMW and RLS. We aimed to evaluate difference in sleep characteristics between patients with RLS with PLMW and those without PLMW. Methods: Our study included twenty eight RLS patients. Subjects underwent suggested immobilization test (SIT) prior to one full-night polysomnography study. Patients were classified into two groups according to the presence of PLMW based on SIT-PLMW index. Polysomnographic findings, subjective sleep quality, and hematologic results were analyzed and compared between the two groups. Results: Mean age of patient with frequent PLMW (SIT-PLMW $\geq 40 / \mathrm{hr}$ ) was significantly higher. RLS patients with frequent PLMW were also significantly related to insomnia severity. The PLMS index was higher in patients with PLMW and showed a significant correlation with the PLMW index. Conclusions: PLMW influence sleep quality such as insomnia and is correlated with movement during sleep.

J Sleep Med 2018;15(2):62-67

Key Words: Restless legs syndrome, Periodic leg movement during sleep, Periodic leg movement during wakefulness, Polysomnography, Suggested immobilization test.
서 론

하지불안증후군은 흔한 감각운동 신경질환으로 안정 시에 불편한 느낌과 다리를 움직이고 싶은 충동이 발생하고 저녁 이나 야간에 증상이 악화되는 양상을 보인다. ${ }^{1-3}$ 이러한 임상 적 특징으로 인하여 수면장애나 불면증 등을 동반하여 삶의 질 저하를 가져올 수 있다.

수면 중에 주기적으로 반복되는 불수의적인 다리의 움직 임을 수면 중 주기성 사지운동(periodic limb movement in sleep, PLMS)이라고 하며 하지불안증후군 환자들의 약 80 $90 \%$ 가 수면 중 주기성 사지운동을 보인다고 알려져 있다. ${ }^{4}$ 주

This is an Open Access article distributed under the terms of the Creative Commons Attribution Non-Commercial License (https://creativecommons.org/licenses/by-nc/4.0) which permits unrestricted non-commercial use, distribution, and reproduction in any medium, provided the original work is properly cited.
기성 사지운동이 정상인에서도 관찰되며 연령과 양의 상관 관계를 보인다는 보고도 있으며 폐쇄성 수면 무호흡증과 같 은 다른 수면 질환 등에서도 나타날 수 있다. 5,6 수면 중 주기 성 사지운동 동반 여부에 따른 하지불안증후군의 임상적 차 이에 관한 비교적 많은 연구들이 이루어졌는데 하지불안증 후군의 중증도와 유의한 연관성을 보인다는 결과도 있으나, ${ }^{7}$ 연관성이 없다는 결과도 있어서 중증도와의 관련성은 일관 된 결과를 보이지는 않았다. ${ }^{8}$ 또한 수면 중 주기운동이 하지 불안증후군 환자에서 주관적 수면 증상에 영향을 미치지 않 으며 수면구조상 렘수면 잠복기를 줄이며 자발적 각성 빈도 를 높인다는 보고도 있다. ${ }^{9}$

하지불안증후군의 약 $1 / 3$ 에서 각성 시에도 주기성 운동을 보이는 것으로 알려져 있는데 각성 중 주기운동에 대한 연구 는 많이 이루어지지는 않았다. ${ }^{10}$ 운동억제검사(suggested 
immobilization test, SIT)는 각성 상태에서 주기성 사지운동 을 평가하는 검사방법으로 하지의 감각운동 증상을 정량화 할 수 있다. Montplaisir 등에 의해 SIT 검사 중 1 시간에 40 회 이상 주기성 사지운동이 나타날 경우 비교적 높은 민감도 (81\%)와 특이도 $(81 \%)$ 로 하지불안증후군을 진단할 수 있다고 보고되었다. ${ }^{11} \mathrm{SIT}$ 는 검사 시간이 60 분 정도 소요되어 수면 다원검사보다 간편하게 이용할 수 있고 일주기 리듬에 따른 감각운동 증상을 일중 여러 번 시행할 수 있는 장점이 있다.

하지불안증후군 환자에서 수면 전 감각운동의 정도가 수 면에 영향을 주는지 평가한 연구는 잘 알려져 있지 않다. 저 자들은 하지불안증후군 환자에서 SIT를 통한 각성 중 주기 성 사지운동의 중등도에 따라 수면 관련 증상과 수면구조가 차이가 있는지 알아보았다.

\section{방 법}

\section{대 상}

2007년 1월부터 2009년 5월까지 강동경희대학교병원 수 면센터에서 특발성 하지불안증후군을 진단받고 수면다원검 사 시행 전 운동억제검사를 시행한 28 명의 20세 이상 성인 환자를 대상으로 하였다. 하지불안증후군은 2003년 International restless leg syndrome (IRLS) Study Group Criteria의 임상적 진단기준에 따라 진단하였으며 중등도의 폐쇄성 수 면 무호흡(apnea and hypopnea index $>15 / \mathrm{hr}$ ) 또는 다른 수면 질환, 신경학적 또는 정신과적인 질환을 동반하는 자와 다른 질병과 동반하여 이차성 하지불안증후군으로 진단된 환 자는 제외하였다. ${ }^{2}$ 수면 중 주기성 사지운동의 경우 수면장애 의 국제 분류 3판(International Classification of Sleep Disorder-Third edition)에 따라서 수면 중 주기성 사지운동 지수 (PLMS index, PLMSI)가 15 이상인 경우로 정의하였다. ${ }^{12}$ 각성 중 주기성 사지운동 지수(periodic limb movement in wakefulness index, PLMWI)는 기존 연구에 따라 ${ }^{11}$ SIT에서 periodic limb movement in wakefulness (PLMW)가 시간당 40 회를 기준으로 하지불안증후군 환자들을 두 군으로 각각 나누어 수면설문검사 및 수면다원검사 결과를 비교 분석하 였다. 본 연구는 후향적 연구이며 강동경희대학교병원 임상 시험심사위원회(IRB)의 승인을 받았다.

\section{설문지}

환자들의 주관적 수면 증상을 평가하기 위해 수면다원검 사 전에 다음과 같은 수면 설문지를 작성하였다. 피츠버그 수면의 질 지수(Pittsburgh Sleep Quality Index), ${ }^{13}$ 엡워스 졸 음 척도(Epworth Sleepiness Scale), ${ }^{14}$ 불면증 심각성 척도
(Insomnia Severity Index), ${ }^{15}$ 벡 우울 척도(Beck Depression Inventory). ${ }^{16}$ 피츠버그 수면의 질 지수는 환자의 4 주 동안 수 면의 질과 양상을 평가하며 엡워스 졸음 척도는 8 문항, 불면 증 심각성 척도는 7문항으로 이루어진 자가 평가 설문 도구 로 각각 주간 졸음 및 불면증을 반영하며 벡 우울 척도는 0 3점으로 점수를 평가하는 21개의 문항을 설문 조사하여 환자의 정서를 평가하였다.

\section{Polysomnography}

연구에 참여한 모든 환자들은 야간수면다원검사를 실시하 였고 뇌파, 안전도 감지기, 심전도, 흥곽 및 복부 호흡 측정 장치, 혈중 산소 농도 측정기, 양쪽 하악 및 전경골근 근전도 검사 장치를 이용하여 수면 상태와 주기성 사지운동 등에 대 하여 평가하였다. 주기성 사지운동은 0.5 초에서 10 초 동안 지속되는 움직임이 5 초에서 90 초 사이의 간격을 두고 최소 한 4 회 이상 분리되어 나타나는 경우로 정의하였다. ${ }^{12}$

주기성 사지운동의 빈도 평가를 위하여 사지운동 총 횟수 를 총 수면 시간으로 나눈 값을 지수로 사용하여 각각 수면 중 주기성 사지운동 지수(PLMSI), 수면 중 전체 사지운동 지수 (total limb movement in sleep index), 주기성 사지운동 관련 각성 지수(periodic limb movement arousal index, PLMAI) 를 계산하였다.

\section{Suggested immobilization test}

운동억제검사는 하지의 감각운동 증상을 평가하기 위하여 야간수면다원검사 전에 각성 상태 동안 시행하였다. 21 시경 부터 약 1 시간 동안 시행하였고 환자는 검사하는 동안 눈을 뜨고 각성 상태를 유지하도록 교육 후 45도 경사의 침대에 다리를 편 상태를 유지하도록 하였다. 각성 상태 유지 여부 및 운동 증상을 평가하기 위해 뇌파검사 장비 및 표면 근전 도검사 장비를 양쪽 전경골근(tibialis anterior) 및 머리에 부 착하였다. 운동억제검사를 통해서 각성 중 주기성 사지운동 지수(PLMWI), 전체 사지운동 지수(total limb movement during wake index)를 평가하였고 전체 사지운동 지수는 주 기성을 갖지 않는 사지 움직임을 포함하는 계산법으로 10초 이상 지속되며 5 90초 사이의 간격을 나타내는 일련의 움직 임이 4회 이상 연속적으로 나타나지 않는 경우도 모두 포함 하는 것으로 정의하였다. ${ }^{12}$

\section{통계 분석}

통계 분석은 SPSS version 22.0(IBM Corp., Armonk, NY, USA)을 이용하였다. 두 군에서 수면설문검사, 운동억제검사 및 야간수면다원검사 결과를 비교하였으며 군 간의 차이는 
Mann-whitney u test와 chi-square test를 사용하여 분석하 였고 운동억제검사와 수면다원검사에서 측정한 주기성 사지 운동 지수의 연관성을 알아보기 위하여 Spearman correlation analysis를 이용하였다. $p$ 값이 0.05 미만인 경우 통계적으로 유의한 것으로 판정하였다.

\section{결 과}

하지불안증후군을 진단받은 28명의 환자들 중에서 PLMW 지수가 40 미만인 환자[restless leg syndrome(RLS)-PLMW] 는 19명이었고 40세 이상인 환자(RLS+PLMW)는 9명이었 다. 전체 환자의 평균 연령은 57 세였으며, $42.9 \%$ 가 남자였다. 평균 연령은 RLS+PLMW군이 RLS-PLMW군보다 유의하 게 높았으며(66.1 \pm 14.5 세 vs. $53.0 \pm 11.1$ 세, $p=0.041$ ) 성별에 차이는 없었다. 설문 결과를 비교하였을 때 RLS+PLMW군 에서 불면 증상을 더 심하게 호소하였으나(21.4 \pm 5.4 vs. 13.7 $\pm 6.4, p=0.007)$, 우울, 주간 졸림, 수면의 질은 차이가 없었다 (Table 1).

수면다원검사 결과에서 PLMW 정도에 따라 총 수면 시 간, 수면 잠복기와 수면 효율의 차이는 없었다. 또한 수면구 조와 입면 후 각성 시간 및 무호흡-저호흡 지수에서도 유의 한 차이는 없었다(Table 2).

수면 중 주기성 사지운동은 RLS+PLMW군에서 RLSPLMW군에 비해 유의하게 많았으며[periodic limb movement index (PLMI) 69.9 $\pm 66.3 / \mathrm{hr}$ vs. 28.5 $\pm 28.1 / \mathrm{hr}, p=0.046]$, 전체 사지운동 또한 더 빈번하게 관찰되었다(total $\mathrm{limb}$ movement index $70.9 \pm 65.9 / \mathrm{hr}$ vs. $30.7 \pm 28.7 / \mathrm{hr}, p=0.046$ ). 하지만 수면 중 주기성 사지운동 여부를 평가하는 기준인

Table 1. Demographic characteristics lab and sleep questionnaire results

\begin{tabular}{lccc}
\hline & $\begin{array}{c}\text { RLS-PLMW } \\
(\mathrm{n}=19)\end{array}$ & $\begin{array}{c}\text { RLS+PLMW } \\
(\mathrm{n}=9)\end{array}$ & $p$-value* \\
\hline Age & $53(11.1)$ & $66.1(14.5)$ & 0.041 \\
Sex & $4(50.0)$ & $7(41.2)$ & 0.678 \\
BDI & $12.0(8.1)$ & $17.7(9.7)$ & 0.16 \\
SSS & $2.7(1.3)$ & $4.1(2.1)$ & 0.116 \\
ESS & $6.4(2.4)$ & $6.2(5.1)$ & 0.427 \\
ISI & $13.7(6.4)$ & $21.4(5.4)$ & 0.007 \\
PSQI & $18.0(4.3)$ & $18.3(5.3)$ & 0.98 \\
\hline
\end{tabular}

RLS-PLMW: PLMW <40/hr, RLS+PLMW: PLMW $\geq 40 /$ hr. Mean (standard deviation). *chi-square test and Mann-Whitney test. RLS: restless leg syndrome, PLMW: periodic limb movement during wakefulness, BDI: Beck Depression Inventory, SSS: Stanford sleepiness scale, ESS: Epworth sleepiness scale, ISI: insomnia severity index, PSQI: Pittsburg sleep quality index
PLMI $>15 / \mathrm{hr}$ 또는 PLMI $>5 / \mathrm{hr}$ 를 만족하는 환자 비율은 두 군 간 유의한 차이가 없었다( $p$-value 각각 $0.439,0.609)$. 또 한 수면 중 주기성 사지운동 관련 각성은 두 군 간 차이를 보 이지 않았다(PLMAI 25.0 $\pm 43.2 / \mathrm{hr}$ vs. $11.9 \pm 13.2 / \mathrm{hr}, p=0.376$ ) (Table 3). 또한 수면 중 주기성 사지운동의 빈도와 각성 중 주기성 사지운동의 빈도의 연관성을 평가하였을 때 유의한 양의 상관관계를 확인할 수 있었다 $(\mathrm{r}=0.530, p=0.006$, respectively) (Fig. 1).

Table 2. Sleep characteristics of patients

\begin{tabular}{|c|c|c|c|}
\hline & $\begin{array}{c}\text { RLS-PLMW } \\
\quad(n=19)\end{array}$ & $\begin{array}{c}\text { RLS+PLMW } \\
(n=9)\end{array}$ & $p$-value \\
\hline $\mathrm{TST}(\min )$ & $327.4(41.3)$ & $302.9(61.7)$ & 0.431 \\
\hline N1 (\%) & $18.1(6.4)$ & $32.8(22.2)$ & 0.640 \\
\hline N2 (\%) & $36.9(10.8)$ & $32.6(12.0)$ & 0.363 \\
\hline N3 (\%) & $26.5(10.9)$ & $26.2(15.4)$ & 0.902 \\
\hline REM (\%) & $18.7(7.0)$ & $16.8(8.6)$ & 0.571 \\
\hline WASO (\%) & $16.0(8.1)$ & $24.3(16.3)$ & 0.313 \\
\hline SE (\%) & $82.4(8.1)$ & $74.1(16.3)$ & 0.268 \\
\hline $\mathrm{SL}(\min )$ & $35.0(34.1)$ & $40.0(35.4)$ & 0.669 \\
\hline $\mathrm{AI}(/ \mathrm{hr})$ & $32.6(14.4)$ & $51.3(38.8)$ & 0.210 \\
\hline AHI (/hr) & $3.8(5.2)$ & $7.3(14.5)$ & 0.729 \\
\hline RDI (/hr) & $8.5(8.7)$ & $13.1(19.4)$ & 1 \\
\hline $\mathrm{LowSaO}_{2}(\%)$ & $89.1(4.2)$ & $89.0(4.4)$ & 0.64 \\
\hline
\end{tabular}

RLS-PLMW: PLMW <40/hr, RLS+PLMW: PLMW $\geq 40 /$ hr. Mean (standard deviation). ${ }^{*}$ chi-square test and Mann-Whitney test. RLS: restless leg syndrome, PLMW: periodic limb movement during wakefulness, TST: total sleep time, REM: rapid eye movement, WASO: wake after sleep onset, SE: sleep efficacy, SL: sleep latency, AI: arousal index, AHI: apnea-hypopnea index, RDI: respiratory disturbance index, $\mathrm{SaO}_{2}$ : oxygen saturation

Table 3. Polysomnographic and SIT measurements in patients

\begin{tabular}{lcrc}
\hline & $\begin{array}{c}\text { RLS-PLMW } \\
(\mathrm{n}=19)\end{array}$ & $\begin{array}{c}\text { RLS+PLMW } \\
(\mathrm{n}=9)\end{array}$ & p-value* \\
\hline SIT-TLMI (/hr) & $44.9(56.4)$ & $109.8(51.4)$ & 0.002 \\
SIT-PLMI (/hr) & $11.1(12.3)$ & $105.6(53.3)$ & $<0.001$ \\
TLMI (/hr) & $30.7(28.7)$ & $70.9(65.9)$ & 0.046 \\
PLMI (/hr) & $28.5(28.1)$ & $69.9(66.3)$ & 0.046 \\
PLMI >5/hr & $13(68.4)$ & $7(77.8)$ & 0.609 \\
PLMI >15/hr & $12(63.2)$ & $7(77.8)$ & 0.439 \\
PLMAI (/hr) & $11.9(13.2)$ & $25.0(43.2)$ & 0.376 \\
\hline
\end{tabular}

RLS-PLMW: PLMW <40/hr, RLS+PLMW: PLMW $\geq 40 / \mathrm{hr}$. Mean (standard deviation). *chi-square test and Mann-Whitney test. RLS: restless leg syndrome, PLMW: periodic limb movement during wakefulness, SIT: suggested immobilization test, TLMI: total limb movement index, PLMI: periodic limb movement index, PLMAI: periodic limb movement arousal index 


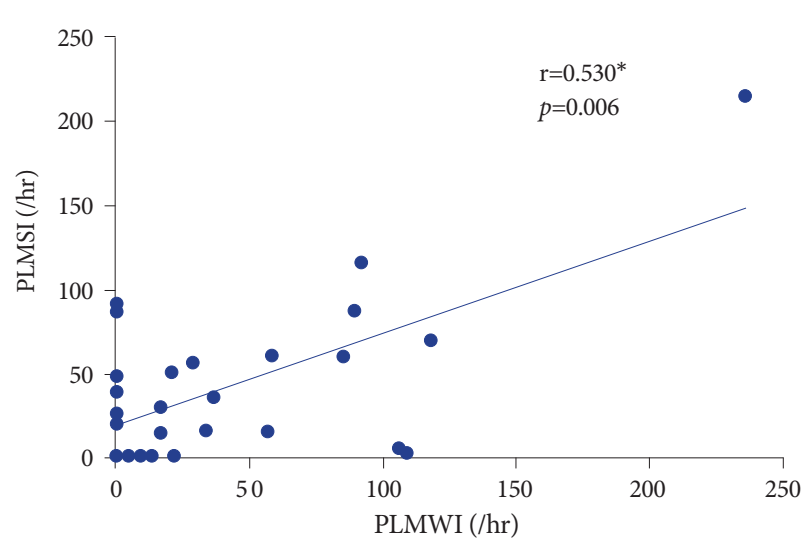

Figure 1. Correlation of between PLMSI and PLMWI. *Spearman correlation analysis. PLMSI: periodic limb movement in sleep index, PLMWI: periodic limb movement during wakefulness index.

\section{고 찰}

본 연구에서 저자들은 하지불안증후군 환자의 각성 중 감 각운동 정도에 따른 수면 관련 증상과 수면구조의 차이를 확 인하였다. 각성 중 주기성 사지운동이 빈번하게 나타난 하지 불안증후군 환자들의 연령이 더 높았고 더 심한 불면증을 호 소하였다. 또한 각성 중 주기 사지운동이 많을수록 수면 중 주기 사지운동의 빈도가 높음을 확인하였다.

연구에 참여한 전체 하지불안증후군 환자들의 평균 PLMW 지수는 41.5 이고 약 $32 \%$ 에서 40 이상을 나타냈다. 하지불안증 후군 환자들에서 시행한 이전 운동억제검사 연구들에서 PLMW 의 빈도는 다양한 결과를 보였는데 Montplaisir 등은 16 명의 하지불안증후군 환자 중 13명(81\%)에서 PLMW > 40을 보인 다고 보고하였고(전체 평균 PLMW: 76.1 \pm 9.6 ), ${ }^{11}$ Michaud 등은 100 명 중 62 명(62\%)에서 PLMW >12 이상을 만족하였 다고 보고하였다(전체 평균 PLMW: $53.3 \pm 62.8$ ). ${ }^{17}$ 또한 Ferri 등은 90명 중 74명(82\%)에서 PLMS와 PLMW 모두 5 이상, 68명(76\%)이 10 이상, 59명(66\%)이 15 이상을 만족하 였다고 보고하였다(전체 평균 PLMW: $56.6 \pm 49.15) .{ }^{10}$ 초기 연구 결과에 비해 후속 연구 결과에서는 PLMW의 평균값이 작고 index cut off value 등을 낮추었는데도 더 적은 비율의 환자들이 포함되었는데 초기 연구에서는 증상이 매우 심한 환자들을 대상으로 하였기 때문에 이러한 차이를 보이는 것 으로 생각된다. 이후 다양한 중증도를 보이는 환자들을 대상 으로 한 연구들은 이를 보완하기 위하여 주관적인 증상에 대 한 평가 척도(mean subjective leg discomfort score during $\mathrm{SIT}, \mathrm{SIT} \mathrm{MDS}$ )를 추가하여 하지불안증후군 진단에 있어서 높은 민감도 및 특이도를 보인다고 하였고, ${ }^{17}$ PLMW 및 감각 증상(SIT MDS) 모두 하지불안증상의 중증도(IRLS scale)와 연관이 있었으며, ${ }^{18}$ 하지불안 증상의 중증도에 따라 PLMW
동반율에 차이가 있을 것이다. 하지만 본 연구에서는 하지불 안 증상을 평가하지 못하여 초기 연구처럼 주기운동에 대한 평가만을 하여서 cut off value 기준을 40으로 정하였다. 본 연구에서 이전 연구보다 PLMW가 낮은 이유는 증상 중증도 가 다양한 환자들이 포함되면서 비교적 증상이 심하지 않은 환자들이 많아서 차이가 발생한 것으로 생각한다.

본 연구에서 평균 PLMS 지수는 41.8로 전체 환자의 $67.9 \%$ 에서 PLMI가 15 이상, $71.4 \%$ 에서 PLMI가 5 이상이었다. 이 는 Shin 등이 국내 하지불안증후군 환자 354 명에서 보고한 비율인 약 $42.3 \%, 57.9 \%$ 보다 높은 수치였다. ${ }^{19}$ 이는 본 연구 에 참여한 환자들의 평균 연령이 높고 남성의 비율도 많았기 때문으로 생각한다.

본 연구에서 각성 중 주기 사지운동을 동반한 하지불안증 후군 환자들의 평균 연령이 더 높았고 이전 연구 결과와 일 치하였다. ${ }^{20}$ 하지불안증후군의 유병률이나 중증도가 나이가 들수록 높아지는 경향을 보이기 때문에 각성 중 주기 사지운 동 역시 같은 양상을 보이는 것으로 생각한다. 하지불안증후 군은 만성적인 신경계 질환으로서 수면장애 및 정서장애 등 의 삶의 질에 많은 영향을 미친다. 증상이 심할수록 수면 잠 복기가 길고 수면 시간도 짧아서 결국 다양한 불면 증상과 주간 졸림 및 정서장애 증상을 호소하게 된다. ${ }^{21,22}$ 이는 피질 활성화를 통한 각성과 자율신경 활성화로 인하여 나타나는 것으로 알려져 있다. 23

각성 중 주기성 사지운동이 수면에 미치는 영향에 대해서 는 많은 연구가 이루어지지는 않았는데 본 연구에서는 각성 중 주기운동 증상이 많을수록 불면증의 중등도가 심해지는 결과를 보였다. 하지만 각성 중 주기성 사지운동 유무에 따 른 수면구조와 객관적 수면 지표의 차이는 없었다. 각성 중 주기성 사지운동은 수면 중 주기성 사지운동과 같이 도파민 활성장애로 나타났을 것으로 생각된다. 기존 하지불안증후 군 환자에서 양성자 자기공명분광법을 이용한 연구 결과 시 상의 도파민 활성은 수면 중 각성과는 제한된 관련성을 보이 지만 주기성 사지운동과는 강한 연관성을 보였다. 반면 글루 탐산염(glutamate) 활성의 증가는 수면 중 각성과 연관성이 높았으나 수면 중 주기성 사지운동과는 관계가 없었다. ${ }^{24}$ 또 한 도파민 효현제가 글루탐산염 분비를 억제하는 가바펜틴 보다 환자들의 주기성 사지운동을 개선시키지만 수면에 영 향이 적었다. ${ }^{25}$ 이런 결과는 도파민 활성장애로 나타나는 각 성 중 주기성 사지운동 또한 객관적 수면에 영향이 제한적인 본 연구 결과를 뒷받침하는 것이다.

각성 중 주기성 사지운동은 수면 중 주기성 사지운동과 양 의 상관관계를 보였다. 이는 이전 연구와 유사한 결과로 Ferri 등은 90명의 특발성 하지불안증후군 환자들에서 PLMW 지 
수와 PLMS 지수 간에 연관성은 있으나 강한 연관성을 보이 지는 않았다고 하였다(correlation coefficient $=0.310, p<$ 0.00003).$^{10}$ 수면 중 주기성 사지운동과 하지불안증후군 둘 다 중추신경계 도파민 활성의 장애로 나타난다고 알려져 있다. 하지불안증후군 증상 및 주기성 사지운동 증상에 도파민 효 현제가 치료에 효과가 있고 ${ }^{26-28}$ 뇌척수액(cererbrospinal fluid) 에서 자유 도파민(free dopamine)과 대사물질인 호모바니린 산(homovalnilic acid)이 증가된 소견을 보이며, ${ }^{26,29}$ 하지불안 증후군과 주기성 사지운동 환자 모두에서 에프 도파 방사성 동위원소(6-[18F] fluoro-L-dopa)를 이용한 양전자 방출 단 층 촬영(Positron Emission Test)에서 흑질선조체의 시냅스 전 도파민 경로의 활성 저하를 보이는 소견들이 이를 뒷받침 한다. ${ }^{30}$ 각성 중 나타나는 움직임도 이러한 도파민 활성장애 와 연관성을 시사하는 것으로 생각한다. 다만 본 연구 및 이 전의 연구가 강한 연관성을 보이지 않은 소견에 대해서는 추 가적인 연구가 필요하다.

연구의 제한점은 연구 대상 표본의 크기가 작았기 때문에 환자군의 연령 차이가 있었으나 보정하지 못하였다. 또한 하 지불안증후군의 중등도에 대한 평가(IRLS Severity Scale)나 운동억제검사에서 주관적 감각 증상 평가(SIT MDS) 등을 시행하지 못하였다. 운동억제검사는 비교적 짧은 시간에 평 가가 이루어지기 때문에 위음성의 제한점도 고려해야겠다. ${ }^{17}$

본 연구는 처음으로 하지불안증후군에서 각성 중 주기성 사지운동 증상에 따른 주관적, 객관적 수면장애를 평가한 것 으로 기존 국내에서 보고된 적이 없어 가치가 높다. 각성 중 증상은 하지불안증후군 환자가 가장 불편을 느끼는 증상으 로 각성 중 증상은 객관적 수면구조의 변화는 없었으나, 주 관적 불면 증상을 악화시켰다. 또한 저자들은 수면 중 주기 성 사지운동과의 연관성을 확인하였다. 도파민 약물 치료 후 각성 중 운동의 변화를 확인하는 것이 그 기전을 확인하는 데 중요할 것으로 사료되며 이에 대한 추가적인 연구가 필요할 것이다.

\section{REFERENCES}

1. Cho YW, Shin WC, Yun CH, et al. Epidemiology of restless legs syndrome in Korean adults. Sleep 2008;31:219-223.

2. Allen RP, Picchietti D, Hening WA, Trenkwalder C, Walters AS, Montplaisi J. Restless legs syndrome: diagnostic criteria, special considerations, and epidemiology. A report from the restless legs syndrome diagnosis and epidemiology workshop at the National Institutes of Health. Sleep Med 2003;4:101-119.

3. Allen RP, Earley CJ. Restless legs syndrome: a review of clinical and pathophysiologic features. J Clin Neurophysiol 2001;18:128-147.

4. Montplaisir J, Boucher S, Poirier G, Lavigne G, Lapierre O, Lespérance P. Clinical, polysomnographic, and genetic characteristics of restless legs syndrome: a study of 133 patients diagnosed with new standard criteria. Mov Disord 1997;12:61-65.

5. Ferri R, Manconi M, Lanuzza B, et al. Age-related changes in periodic leg movements during sleep in patients with restless legs syndrome. Sleep Med 2008;9:790-798.

6. Eun MY, Seok HY, Kim JB, Jung KY. Comparison of sleep quality and polysomnographic findings in patients with RLS according to the presence of periodic limb movements during sleep. J Korean Sleep Res Soc 2011;8:4-8.

7. Garcia-Borreguero D, Larrosa O, de la Llave Y, Granizo JJ, Allen R. Correlation between rating scales and sleep laboratory measurements in restless legs syndrome. Sleep Med 2004;5:561-565.

8. Hornyak M, Hundemer HP, Quail D, Riemann D, Voderholzer U, Trenkwalder C. Relationship of periodic leg movements and severity of restless legs syndrome: a study in unmedicated and medicated patients. Clin Neurophysiol 2007;118:1532-1537.

9. Lee HB, Song ML, Koo BB, Cho YW. Mood symptoms and restless legs syndrome without periodic limb movements during sleep: is it a clinical subtype? J Neuropsychiatry Clin Neurosci 2017;29:52-59.

10. Ferri R, Manconi M, Plazzi G, et al. Leg movements during wakefulness in restless legs syndrome: time structure and relationships with periodic leg movements during sleep. Sleep Med 2012;13:529-535.

11. Montplaisir J, Boucher S, Nicolas A, et al. Immobilization tests and periodic leg movements in sleep for the diagnosis of restless leg syndrome. Mov Disord 1998;13:324-329.

12. American Academy of Sleep Medicine. International classification of sleep disorders. 3rd ed. Darien: American Academy of Sleep Medicine, 2014.

13. Sohn SI, Kim DH, Lee MY, Cho YW. The reliability and validity of the Korean version of the Pittsburgh Sleep Quality Index. Sleep Breath 2012; 16:803-812.

14. Cho YW, Song ML, Morin CM. Validation of a Korean version of the insomnia severity index. J Clin Neurol 2014;10:210-215.

15. Cho YW, Lee JH, Son HK, Lee SH, Shin C, Johns MW. The reliability and validity of the Korean version of the Epworth sleepiness scale. Sleep Breath 2011;15:377-384.

16. Sung HM, Kim JB, Park YN, Bai DS, Lee SH, Ahn HN. A study on the reliability and the validity of Korean version of the Beck Depression Inventory-II(BDI-II). J Korean Soc Biol Ther Psychiatry 2008;14:201-212.

17. Michaud M, Paquet J, Lavigne G, Desautels A, Montplaisir J. Sleep laboratory diagnosis of restless legs syndrome. Eur Neurol 2002;48:108113.

18. Garcia-Borreguero D, Kohnen R, Boothby L, Tzonova D, Larrosa O, Dunkl E. Validation of the multiple suggested immobilization test: a test for the assessment of severity of restless legs syndrome (Willis-Ekbom disease). Sleep 2013;36:1101-1109.

19. Shin JW, Koo YS, Lee BU, et al. Prevalence and characteristics of periodic limb movements during sleep in Korean adult patients with restless legs syndrome. J Clin Sleep Med 2016;12:1089-1097.

20. Nicolas A, Michaud M, Lavigne G, Montplaisir J. The influence of sex, age and sleep/wake state on characteristics of periodic leg movements in restless legs syndrome patients. Clin Neurophysiol 1999;110:1168-1174.

21. Broman JE, Mallon L, Hetta J. Restless legs syndrome and its relationship with insomnia symptoms and daytime distress: epidemiological survey in Sweden. Psychiatry Clin Neurosci 2008;62:472-475.

22. Ulfberg J, Bjorvatn B, Leissner L, et al. Comorbidity in restless legs syndrome among a sample of Swedish adults. Sleep Med 2007;8:768772.

23. Ferri R, Zucconi M, Manconi M, Plazzi G, Bruni O, Ferini-Strambi L. New approaches to the study of periodic leg movements during sleep in restless legs syndrome. Sleep 2006;29:759-769.

24. Allen RP, Barker PB, Horská A, Earley CJ. Thalamic glutamate/glutamine in restless legs syndrome: increased and related to disturbed sleep. Neurology 2013;80:2028-2034.

25. Winkelman JW, Bogan RK, Schmidt MH, Hudson JD, DeRossett SE, Hill-Zabala CE. Randomized polysomnography study of gabapentin enacarbil in subjects with restless legs syndrome. Mov Disord 2011;26: 2065-2072. 
26. Akpinar S. Restless legs syndrome treatment with dopaminergic drugs. Clin Neuropharmacol 1987;10:69-79.

27. Brodeur C, Montplaisir J, Godbout R, Marinier R. Treatment of restless legs syndrome and periodic movements during sleep with L-dopa: a double-blind, controlled study. Neurology 1988;38:1845-1848.

28. Montplaisir J, Lorrain D, Godbout R. Restless legs syndrome and periodic leg movements in sleep: the primary role of dopaminergic mech- anism. Eur Neurol 1991;31:41-43.

29. Yokota T, Hirose K, Tanabe H, Tsukagoshi H. Sleep-related periodic leg movements (nocturnal myoclonus) due to spinal cord lesion. J Neurol Sci 1991;104:13-18.

30. Ruottinen HM, Partinen M, Hublin C, et al. An FDOPA PET study in patients with periodic limb movement disorder and restless legs syndrome. Neurology 2000;54:502-504. 